ISSN 1409-2441

www.ucr.ac.cr
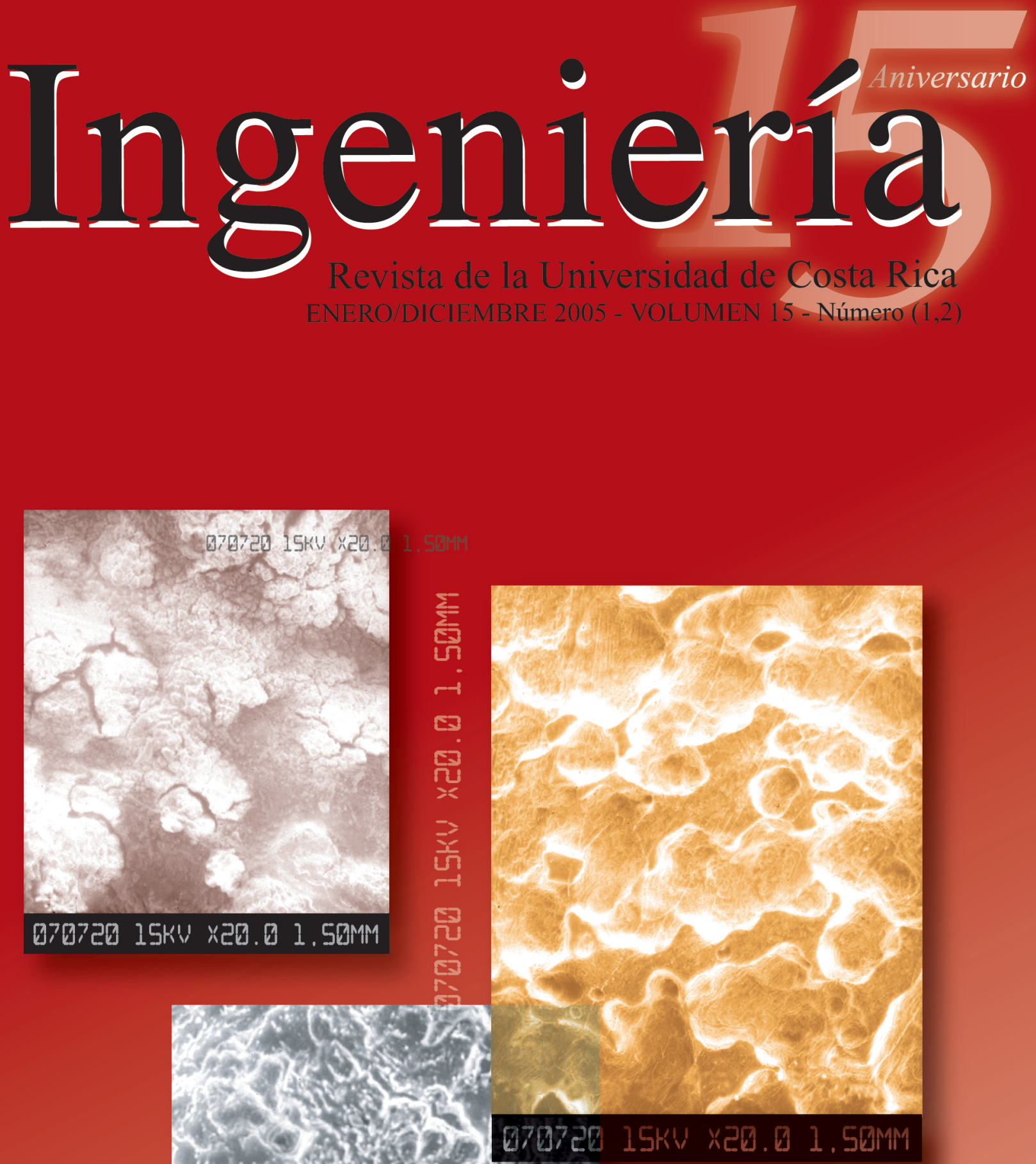

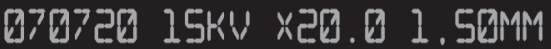

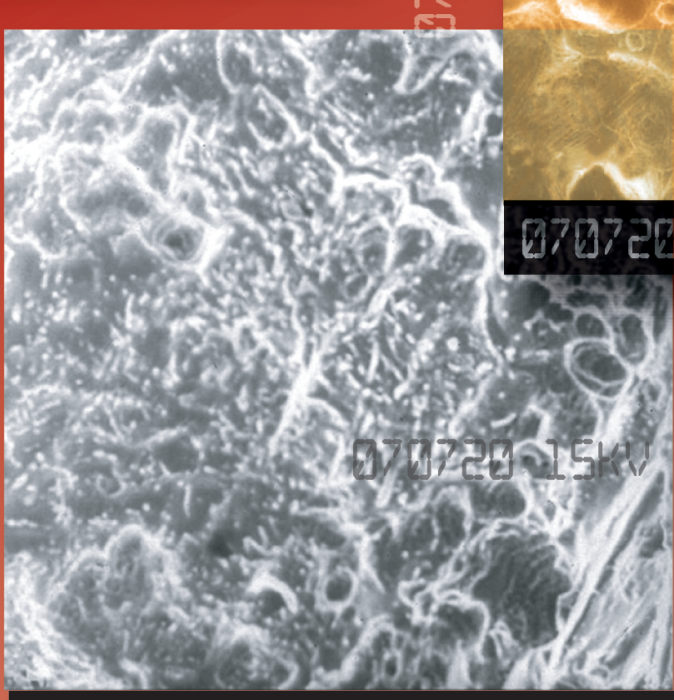

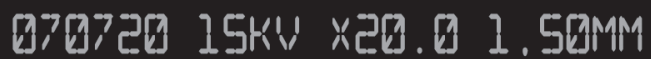




\title{
DETERMINACIÓN DE RESIDUOS DE IMAZAPIC E IMAZAPIR EN ARROZ (ORIZA SATIVA) POR HPLC
}

\author{
Paulina Silva Trejos
}

\begin{abstract}
Resumen
Los residuos de imazapic e imazapir, ambos herbicidas sistémicos de la familia de las imidazolinonas, fueron determinados, previa extracción de las muestras de arroz con solvente de extracción preparado a partir de $40 \mathrm{~mL}$ de $\mathrm{HCl} 1 \mathrm{~N}, 2400 \mathrm{~mL}$ de metanol, grado plaguicida y $1560 \mathrm{~mL}$ de agua. Una alícuota del extracto se concentró hasta aproximadamente $10 \mathrm{~mL}$ en un rotavapor; al extracto concentrado se le adicionó agua y disolución al $10 \% \mathrm{~m} / \mathrm{v}$ de acetato de plomo y se le ajustó el pH a 6,2 con disolución de $\mathrm{NaOH} 1 \mathrm{~N}$. Esta disolución se centrifugó y del líquido sobrenadante se midió una alícuota a la que se le ajustó el pH a 2,1 con disolución de $\mathrm{HCl} 1 \mathrm{~N}$, se extrajo luego con diclorometano y los extractos reunidos se llevaron a sequedad en el rotavapor. Los residuos se disolvieron en agua ultrapura de $\mathrm{pH} 2,5$ y se inyectaron en un cromatógrafo HPLC provisto de una columna $\mathrm{C}_{8}$. Los parámetros de validación

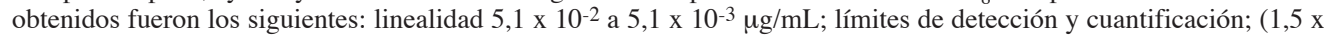
$\left.10^{-3}, 5,0 \times 10^{-3}, 7,8 \times 10^{-3}, 2,6 \times 10^{-3}\right) \mathrm{mg} / \mathrm{mL}$ para el imazapir y el imazapic, que corresponden a $5,0 \times 10^{-2} \mathrm{mg} / \mathrm{kg} \mathrm{de}$ arroz; recuperación, $80 \%$ y $125 \%$ para ambos analitos y repetitividad, desviación estándar para el tiempo de retención 0,003, desviación estándar para el área de 18500 y para la concentración de 0,008.
\end{abstract}

Palabras clave: residuos, pesticidas, arroz, herbicidas, Oriza sativa, HPLC

\begin{abstract}
A requirement to introduce a pesticide in the harvest of any product for the human consume is imperative to determine that it will not leave residues that can injure the human healthy. In this research the residues of imazaphic and imazaphir, both systemic herbicides, were determined en rice (Oriza sativa) by extraction of the samples with the extraction solvent prepared by mixing $40 \mathrm{~mL}$ of $\mathrm{HCl} 1 \mathrm{~N}, 2400 \mathrm{~mL}$ of methanol pesticide grade and $1560 \mathrm{~mL}$ of bidestilated water. To eliminate the impurities the samples extracts were $\mathrm{pH}$ controlled, first to 6,2 and then to 2,1 . An aliquot was injected in HPLC chromatograph with a $\mathrm{C}_{8}$ column. The validation of the analytical method obtained were: $5,1 \times 10^{-2}$ a $5,1 \mathrm{x}$ $10^{-3} \mathrm{mg} / \mathrm{mL}$ for linearity; $\left(1,5 \times 10^{-3}, 5,0 \times 10^{-3}, 7,8 \times 10^{-3}, 2,6 \times 10^{-2}\right) \mu \mathrm{g} / \mathrm{mL}$ for imazapir and imazapic for the detection and quantification limits equivalent to $5,0 \times 10^{-2} \mathrm{mg} / \mathrm{kg}$ in rice; the percent of recovery were $80 \%$ and $125 \%$, for imazapir and imazapic and finally, the precision for the retention time, the area and for concentration were: $0,003 \%$ standard desviation, 18500 and 0,008 , respectively.
\end{abstract}

Key words: residues, pesticides, rice, herbicides, Oriza sativa, HPLC.

Recibido: 21 de octubre del 2004 / Aprobado: 02 de junio del 2005

\section{INTRODUCCIÓN}

El imazapic y el imazapir son herbicidas que pertenecen a la familia de las imidazolinonas. El imazapir tiene la siguiente estructura química mostrada en la Figura 1.

Es estable por un mínimo de dos años a $25^{\circ} \mathrm{C}$, por un año a $37{ }^{\circ} \mathrm{C}$ y por tres meses a $45^{\circ} \mathrm{C}$. Las disoluciones acuosas a $\mathrm{pH}$ entre 5 y 9<smiles>CC(C)C1(C)N=C(c2ncccc2C(=O)O)NC1=O</smiles>

Figura 1. Fórmula química del Imazapir ( \pm )-2-(4,5dihidro-4-metil-4-(1-metiletil)-5-oxo-1H-imidazol2-il)-5-metil-3-acido piridin carboxílico. 
son estables en la oscuridad. La compañía Cyanamid lo comercializó como herbicida, funciona como herbicida sistémico no selectivo, el cual es adsorbido por el follaje y las raíces y distribuido rápidamente al xilema y al floema, la mayor acumulación se presenta en los tejidos meristemáticos. Los residuos en plantas decrecen rápidamente durante las primeras veinticuatro horas y en los suelos la actividad residual varía de seis meses a dos años en climas templados y de tres a seis meses en climas tropicales.

El imazapic tiene la siguiente estructura química:

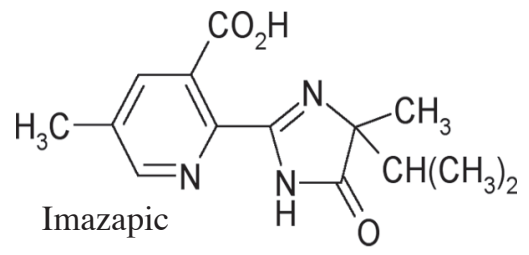

Figura 2. Fórmula química del Imazapic ( \pm )-2-(4,5-dihidro4-metil-4-(1-metiletil)-5-oxo-1H-imidazol-2-il)-5-metil-3acido piridin carboxílico.

También fue introducido por la compañía Cyanamid y funciona como un herbicida de contacto y residual que detiene el crecimiento de las semillas después de ocho horas de la aplicación. Ambos herbicidas, son aplicados, una sola vez durante el ciclo de treinta días después de la germinación del arroz, con bomba de espalda. La cosecha se realiza a los sesenta y ocho días de aplicados los herbicidas.

\section{METODOLOGÍA}

La validación de la metodología se realizó utilizando patrones certificados de ambos analitos de pureza, 99,4 \% y 99,35\%, para el Imazapir e Imazapic, respectivamente. A partir de los mismos, se prepararon disoluciones madre de las cuales, por dilución, se prepararon los patrones para determinar el ámbito de linealidad, la reproducibilidad, los límites de detección y de cuantificación y las recuperaciones (American Chemical Society, 2003).
El tratamiento de las muestras se realizó siguiendo el procedimiento descrito (Cyanamid, 1989). Para ello, se homogeneizaron las muestras y se cuartearon, se mezclaron en proporción dos a uno de muestra a hielo seco, se licuaron en una licuadora previamente lavada y enjuagada con solvente de extracción, hasta que adquirieran apariencia de polvo. Seguidamente, se colocaron en bolsas plásticas, lavadas con solvente de extracción y se guardaron por un mínimo de doce horas en la refrigeradora, hasta lograr la disipación del hielo seco.

Una vez llevadas a temperatura ambiente, se midieron muestras por duplicado de $10 \mathrm{~g}$ en balanza analítica y se extrajeron con $150 \mathrm{~mL}$ de solvente de extracción preparado mezclando $40 \mathrm{~mL}$ de $\mathrm{HCl} 1 \mathrm{~N}, 2400 \mathrm{~mL}$ de metanol, grado plaguicida y $1560 \mathrm{~mL}$ de agua ultrapura; seguidamente, se filtró a través de vidrio fritado cubierto con tierra de diatomea, previamente lavado con acetona y metanol, grado plaguicida. Una alícuota de $25,00 \mathrm{~mL}$ del extracto, se concentró en un rotavapor, marca Buchi modelo RE 121 hasta $10 \mathrm{~mL}$, a una temperatura de (38 \pm 1) ${ }^{\circ} \mathrm{C}$ y $126 \mathrm{r} / \mathrm{min}$.

Al extracto concentrado se le adicionó agua de pH 2,5 y $10 \mathrm{~mL}$ de disolución al $10 \% \mathrm{~m} / \mathrm{v}$ de acetato de plomo y se le ajustó el pH a 6,2 con disolución de $\mathrm{NaOH} 1$ N. Esta disolución se centrifugó por 20 min y del líquido sobrenadante se midió una alícuota de $20 \mathrm{~mL}$ a la que se le ajustó el pH a 2,1 con disolución de $\mathrm{HCl} 1 \mathrm{~N}$, se extrajo luego con diclorometano y los extractos reunidos se llevaron a sequedad en el rotavapor. Los residuos se disolvieron en agua ultrapura de pH 2,5 y se diluyeron a $25,00 \mathrm{~mL}$.

Se inyectaron las muestras en un cromatógrafo de alta resolución, HPLC Perkin Elmer provisto de un detector Ultra Violeta-Visible equipado con una columna $\mathrm{C}_{8}, 2,5 \mathrm{~cm}$ x 4,6 mm y 5,0 $\mu \mathrm{m}$ de diámetro interno, mantenida a $25^{\circ} \mathrm{C}$ con un Column Heater $\mathrm{CH}-30$, eppendorf.

La fase móvil utilizada para el imazapic se prepararó con disolventes como: solvente de extracción preparado con ácido clorhídrico, agua y metanol, disolución reguladora de fosfato 
pH 2,1 preparada a partir de $\mathrm{KH}_{2} \mathrm{PO}_{4}$ ajustando el pH a 2,1 con ácido fosfórico al $85 \%$; la fase móvil para la determinación del imazapic se preparó mezclando $350 \mathrm{~mL}$ de acetonitrilo, 450 $\mathrm{mL}$ de agua y $350 \mathrm{~mL}$ de buffer de fosfato $\mathrm{pH} 2,1$; la fase móvil para la determinación del imazapir se preparó mezclando $350 \mathrm{~mL}$ de acetonitrilo, $580 \mathrm{~mL}$ de agua y $300 \mathrm{~mL}$ de buffer de $\mathrm{pH} 2,1$.

Se realizó un ensayo en blanco siguiendo todo el procedimiento descrito, sin considerar la muestra. Las recuperaciones se realizaron enriqueciendo muestras en el ámbito de linealidad establecido para ambos analitos. Las inyecciones de muestras y patrones se realizaron cinco veces para determinar las desviaciones estándares originadas en las áreas y los tiempos de retención.

Para determinar la repetitividad todas las muestras se realizaron por duplicado y posteriormente, se determinó la desviación estándar obtenida.

\section{RESULTADOS Y DISCUSIÓN}

Las muestras analizadas no corresponden a muestras vendidas comercialmente, sino que corresponden a muestras experimentales obtenidas en parcelas tratadas con un producto comercial a base de los dos herbicidas. A las parcelas se les aplicó únicamente una dosis a los treinta días después de la germinación y la cosecha se realizó a los sesenta y ocho días, después de la aplicación de los herbicidas.

Para la optimización de la metodología aplicada se preparó una disolución madre de ambos analitos a partir de los reactivos de imazapic e imazapir, de pureza $99,3 \%$ y 99,4 \%, respectivamente, con su correspondiente certificado de pureza. A partir de la disolución madre se prepararon disoluciones para evaluar el ámbito de linealidad, encontrándose que los mismos fueron, para el imazapir y el imazapic, de 5,1 x 10-2 $\mu \mathrm{g} / \mathrm{mL}$ a 5,1 x $10^{-3} \mu \mathrm{g} / \mathrm{mL}$, con un coeficiente de correlación de 0,9998 y de $5,1 \times 10^{-2} \mu \mathrm{g} / \mathrm{mL}$ a $5,1 \times 10^{-3} \mathrm{x}$ $10^{-2} \mu \mathrm{g} / \mathrm{mL}$, con un coeficiente de correlación de 0,9947, respectivamente. Los límites de detección y de cuantificación fueron evaluados de acuerdo con (Miller \& Miller,1998) obteniéndose los siguientes resultados, respectivamente $(1,5$ x $\left.10^{-3}, 5,0 \times 10^{-3}, 7,8 \times 10^{-3}, 2,6 \times 10^{-2}\right) \mu \mathrm{g} / \mathrm{mL}$ para el imazapir y el imazapic, que corresponden a 5,0 x $10^{-2} \mathrm{mg} / \mathrm{kg}$ de arroz para ambos analitos. Se obtuvieron recuperaciones para las muestras de arroz enriquecidas en el ámbito de linealidad estudiado entre $80 \%$ y $125 \%$ para ambos analitos.

Las muestras de arroz se trataron previamente antes de la extracción con hielo seco y se dejaron disipar en refrigeración por un mínimo de doce horas; posteriormente, se pesaron y se extrajeron.

Las muestras fueron analizadas inmediatamente después de la cosecha y a los sesenta días. Los resultados obtenidos fueron de $1,1 \times 10^{-1}$ a 1,2 x $10^{-1} \mu \mathrm{g} / \mathrm{mL}$ para el imazapir y de 2,3 x $10^{-2}$ $\mu \mathrm{g} / \mathrm{mL}$ a $4,1 \times 10^{-1} \mu \mathrm{g} / \mathrm{mL}$ para el imazapic en la muestras analizadas inmediatamente después de la cosecha. Las muestras analizadas después de sesenta días informan valores inferiores a los límites de cuantificación determinados.

En la Figura 3, se presenta la curva de calibración obtenida con las disoluciones patrón preparadas a partir de la madre del analito imazapir.

En la Figura 4, se presenta la curva de calibración obtenida con las disoluciones patrón preparadas a partir de la madre del analito imazapic. En el Cuadro 1 se presentan los límites de detección y cuantificación obtenidos para ambos analitos, por medio de las ecuaciones de Miller y Miller (American Chemical Society, 2003).

Los resultados muestran que el tiempo de

Cuadro 1. Límites de detección y cuantificación para en imazapic y imazapir.

$\begin{array}{lll}\text { Analito } & \mathrm{LD} \mu \mathrm{g} / \mathrm{mL} & \mathrm{LC} \mu \mathrm{g} / \mathrm{mL} \\ \text { Imazapic } & 0,0078 & 0,026 \\ \text { Imazapir } & 0,015 & 0,0050\end{array}$

Fuente: (Miller \& Miller, 1998) 


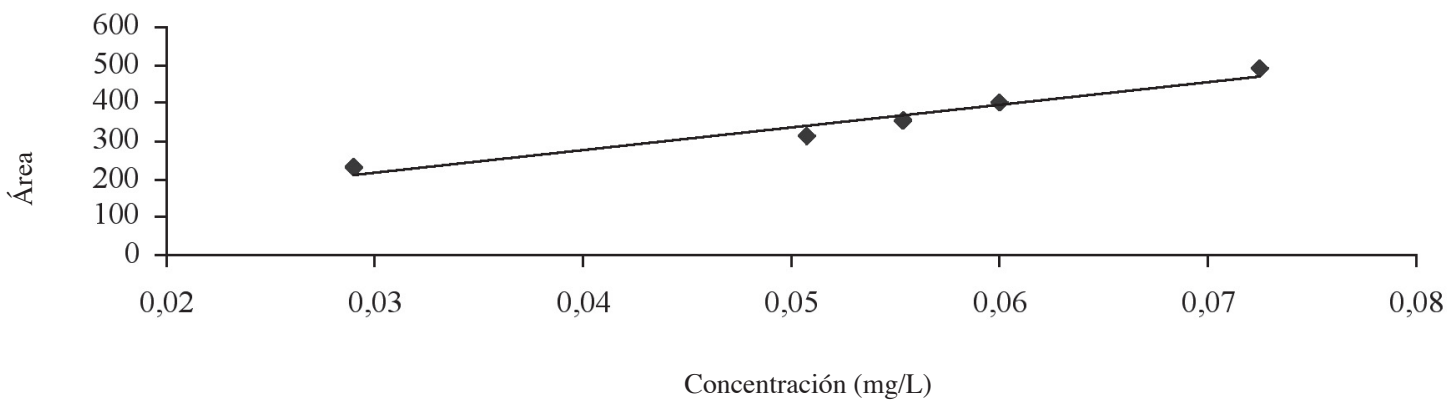

Figura 3. Curva de calibración para Imazapir a tiempo de retención

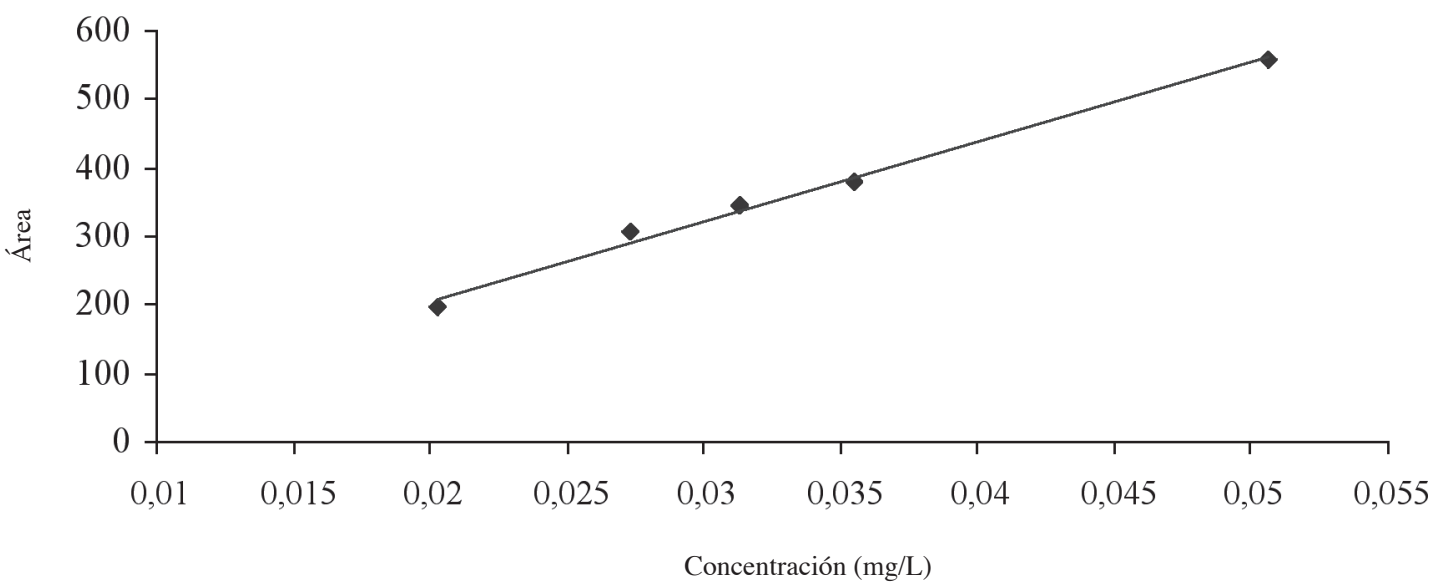

Figura 4. Curva de calibración para Imazapic a tiempo de retención 4,19 min.

Cuadro 2. Repetitividad en los tiempos de retención, en la áreas y en las concentraciones de las muestras analizadas.

Desviación estándar

Tiempo de retención

0,003

Área

18500

Concentración de analito en

0,008
Cuadro 3. Resultados obtenidos para las muestras inmediatamente después de la cosecha (A) y a los sesenta días (B).

$\begin{array}{cll}\text { Muestra } & \begin{array}{l}\text { Imazapic } \\ (\mathrm{mg} / \mathrm{kg})\end{array} & \begin{array}{l}\text { Imazapir } \\ (\mathrm{mg} / \mathrm{kg})\end{array} \\ \text { A1 } & 0,23 \pm 0,07 & 0,11 \pm 0,07 \\ \text { A2 } & 0,41 \pm 0,07 & 0,12 \pm 0,07 \\ \text { B1 } & \text { ND } & \text { ND } \\ \text { B2 } & \text { ND } & \text { ND } \\ \text { B3 } & \text { ND } & \text { ND } \\ \text { B4 } & \text { ND } & \text { ND }\end{array}$

Fuente: (La autora)

Fuente: (La autora) 
conservación de las muestras después de realizada la última aplicación es decisiva para la descomposición de los residuos de ambos herbicidas, ya que las muestras analizadas inmediatamente muestras residuos cuantificables en tanto que las analizadas a los sesenta días no presentan resultados cuantificables.

\section{REFERENCIAS BIBLIOGRAFICAS}

American Chemical Society (2003). How to develop, validate, and troubleshoot GC and HPLC Methods. Academic Press, London.

Basf Corporation. (2002). Certificado de análisis del Imazapic BAS 715 H, Estados Unidos.

Cyanamid. (1998). Determination of residues of Imidazolinones in grains with a validated sensitivity of $0,05 \mathrm{mg} / \mathrm{kg} \mathrm{LAA} /$ $D L$. Academic Press, London.

Cyanamid. (1991). GC Method for the determination of CL 182, 70. Residues in alfalfa forage, May and Seed. Van Nostrand, USA.
Cyanamid. (1989). HPLC Method for the determination of CL 263,499 Residues in drinking water. Water Rev.,New York.

Cyanamid. (2001). Preparación de muestras para el análisis de residuos de imazapic e imazapir en arroz. Van Nostrand, USA.

Cyanamid. (2002). Certificado de análisis del Imazapir BAS 693 H, Estados Unidos.

Miller, J. C. \& Miller, J. N. (1998). Estadística para Química Analítica. Addison-Wesley Iberoamericana.

\section{SOBRE LA AUTORA}

\section{Paulina Silva Trejos}

Licenciada en Química

Master en Administración de Empresas

Profesora e investigadora del Departamento de Química Analítica de la Escuela de Química de la Universidad de Costa Rica Teléfono: 2074870

Correo electrónico: psilva@equi.ucr.ac.cr 
